\title{
HISTÓRIA DA EDUCAÇÃO BRASILEIRA DURANTE O REGIME MILITAR (1964-1985) ${ }^{1}$
}

HISTORY OF BRAZILIAN EDUCATION DURING THE MILITARY REGIME (1964-1985)

\section{Sonia Maria Zanezi Peres}

Secretaria de Estado de Educação de Mato Grosso, Mato Grosso, MT, Brasil. E-mail: soniazanezi@ hotmail.com

DOI: https://doi.org/10.46550/amormundi.v2i2.63

Recebido em: 23.01.2021

Aceito em: 28.02.2021

Resumo: Este texto é uma revisão de literatura, que aborda as questões educacionais durante o período militar, tendo como objetivo demostrar como o regime militar atuava, cerceando direitos e garantias individuais e coletivas da população brasileira, havendo inclusive repressão de manifestações no intuito de "calar" a população brasileira que ousasse discutir assuntos relevantes da nossa sociedade, principalmente a educação.

Palavras-chave: História da educação. Regime militar. Sociedade.

Abstract: This text is a literature review, which addresses educational issues during the military period, with the objective of demonstrating how the military regime worked, restricting the individual and collective rights and guarantees of the Brazilian population, including repression of demonstrations in order to "shut up" the Brazilian population that dared to discuss relevant issues of our society, mainly education.

Keywords: History of education. Military regime. Society.

\section{Introdução}

A bordar o contexto educacional brasileiro durante o regime militar nos faz refletir Asobre momentos de cerceamentos dos direitos e liberdades individuais e coletivas da população brasileira, pois durante os anos de 1964 a 1985, nosso país viveu momentos de repressão e restrição de liberdades.

Neste contexto, propomos dialogar sobre como a estava a educação brasileira durante o período militar, procurando destacar alguns movimentos de estudantes como a União Nacional dos Estudantes (UNE), e decretos e atos expedidos pelos governantes na busca de censurar o direito e liberdade.

Apesar dos governos militares terem ampla parcela da população a seu favor como a classe

1 Este texto é um tópico do capítulo 1 da pesquisa de Mestrado em História da Pontifícia Universidade Católica de Goiás, defendida em 27 de agosto de 2020, pela autora do texto, sendo revisado e atualizado para esta publicaçáo. 
empresarial, que buscava favorecer a modernização da nação, dos quais sustentavam o regime.

\section{Educaçáo brasileira durante o período de 1964-1985}

Estudar a história da educação nos leva, necessariamente, ao estudo da humanidade, haja vista que não existe educação fora de uma sociedade. Para compreender o contexto em que se encontra a educação nos dias atuais é necessário um olhar mais extensivo, para percebermos como as variáveis políticas e econômicas estão interferindo na instituiçẫo escolar onde trabalhamos. Devemos buscar uma reflexão mais ampla em relação à educação e à sociedade, nesse sentido, a educação é resultado de exercícios de conhecimentos relevantes para a existência dos sujeitos, enquanto membros da sociedade.

Inúmeras mudanças ocorreram na educação brasileira e foram implantadas de forma autoritária e centralizadora, sem o envolvimento da sociedade, pois na prática a democracia foi cerceada em vários momentos na história, principalmente no regime militar.

Abordar o contexto educacional brasileiro durante o regime militar nos faz refletir sobre momentos de cerceamentos dos direitos e liberdades individuais e coletivas, tendo o apoio, no primeiro momento, como afirma Ghiraldelli Jr. (2015), da sociedade civil, cabe destacar neste caso que determinada parcela apoiava o regime como a UDN.

Em um primeiro momento, o regime militar instaurado em 1964 contou com apoio civil, ou seja, com lideranças da UDN e outros partidos. Mais tarde, principalmente a partir de 1964 o grupo militar mais conservador do regime cassou os direitos políticos de várias lideranças que apoiavam o golpe [...] os militares que vieram com o golpe de 1964 tinham uma ideia de que a política, os partidos e o Congresso não eram um mal necessário, simplesmente um mal em si mesmo, que deveria ser substituído por outro tipo de política, mais dócil às decisōes tecnocráticas (GHIRALDELLI JR., 2015, p. 146).

Abordar o contexto educacional brasileiro durante o regime militar nos faz refletir sobre momentos de cerceamentos dos direitos e liberdades individuais e coletivas, que teve apoio, no primeiro momento, como afirma Ghiraldelli Jr. (2015), de partidos políticos, pois no

[...] primeiro momento, o regime militar instaurado em 1964 contou com apoio civil, ou seja, com lideranças da UDN e outros partidos. Mais tarde, principalmente a partir de 1964, o grupo militar mais conservador do regime cassou os direitos políticos de várias lideranças que apoiavam o golpe [...] os militares que vieram com o golpe de 1964 tinham uma ideia de que a política, os partidos e o Congresso não eram um mal necessário, simplesmente um mal em si mesmo, que deveria ser substituído por outro tipo de política, mais dócil às decisóes tecnocráticas (GHIRALDELLI JR., 2015, p. 146).

Nesse contexto de cerceamento dos direitos a sociedade brasileira protestava com veemência pela democracia, no sentido de decidir sobre o desenvolvimento do País. Os estudantes faziam parte desse processo e aclamavam também por democracia. Em outubro de 1968, considerado um mês histórico, houve um conflito entre os estudantes da Universidade de São Paulo (USP) e da Mackenzie, pois os grupos de estudantes envolvidos compunham grupos distintos de pensamentos de esquerda (USP) e direita (Mackenzie). A União Nacional dos Estudantes (UNE), Por sua vez, tentou realizar um Congresso que mesmo sendo proibido, foi descoberto pelos militares e muitos dos estudantes envolvidos nessa ação foram presos 
Os militares utilizaram as forças sociais que apoiavam a tomada do poder e passaram a governar o país através de uma tecnoburocracia, não satisfazendo os interesses da sociedade e sim de seus próprios interesses como afirma Ghiraldelli Jr. (2015).

Dentre as primeiras medidas do governo militar foi o Ato Institucional no 1 , de 09 de abril de 1964, que dava ao executivo o poder de cassar parlamentares e suspender direitos políticos de qualquer cidadão. $\mathrm{Na}$ área da educação, os funcionários públicos que não atendessem as ordens eram punidos, podendo ser presos e até torturados, por um estado autoritário que recebia investimentos estrangeiros, como afirma Napolitano (1998).

Contudo, a promulgação do Ato Institucional no 1 (AI-1), em 9 de abril de 1964, dava início à era dos Atos Institucionais, que só terminaria em 1978, demonstrando como o legalismo golpista era artificial. O AI-1, elaborado por Francisco Campos (o redator da Constituição fascista do Estado Novo em 1937), deveria vigorar até 31 de janeiro de 1966. Estabelecia uma série de medidas da sociedade e dos poderes públicos por parte do Executivo (ou seja, o governo federal) tais como: o poder de cassar direitos políticos dos cidadãos, decretar estado de sítio [...] (NAPOLITANO, 1998, p. 16).

Não bastasse o momento de repressão e supressão de direitos, o Executivo recebia amplos poderes para melhor controlar a Nação, como afirma Dockhorn (2002), pois

o AI-2 estabeleceu a continuação das premissas da Doutrina de Segurança Nacional que propunha a paz social como elemento condicionante do desenvolvimento. Além da manutenção das medidas do primeiro ato, AI-2 possibilitou ao Executivo a competência das questóes orçamentárias e de regulamentação das forças Armadas: exclusividade para decretar ou prorrogar o "estado de sítio", direito de baixar atos complementares, decretos-leis e recesso do Congresso Nacional, Assembleia Legislativa e Câmara dos Vereadores. (DOCKHORN, 2002, p. 45).

Percebemos que em relação a democracia, neste momento foi completamente cerceada, onde militares impunham suas vontades através de atos administrativos, forçando a população a aceitar, neste caso concordamos com Freire (1986), que apontava que o diálogo faz-se necessário para o desenvolvimento, o autor ainda aponta que nosso país nasceu e cresceu dentro condiçôes negativas em relação a experiências democráticas, pois o

Brasil nasceu e cresceu sem experiência de diálogo. De cabeça baixa, com receio da Coroa. Sem imprensa. Sem relaçóes. Sem sentido marcante de nossa colonização, fortemente predatória, à base da exploração econômica do grande domínio [...] escravo inicialmente do nativo e posteriormente do africano, não teria criado condiçóes necessárias ao desenvolvimento de uma mentalidade permeável, flexível, característica do clima cultural democrático, no homem brasileiro (FREIRE, p. 66-67, 1986).

Apesar dos interesses do governo militar em cercear direitos, alguns setores que segundo Romanelli (2013), foram fortalecidos como o empresariado, no sentido de favorecer a modernização da Nação e os interesses de grupos que sustentavam o regime, como afirma a autora, destacando também o papel da educação como fator de desenvolvimento:

Se o significado da educaçáo como fator de desenvolvimento foi percebido desde o início da implantação do novo regime, isso não foi demonstrado, pelo menos em toda a sua plenitude, senão a começar em 1968. Como esse ano assinala também o início de mudanças mais profundas na vida da sociedade e da economia - já que foi a época em que a expansão foi retomada de forma mais acelerada - pode-se perceber que o sistema educacional foi marcado por dois momentos nitidamente 
definidos em sua evolução a partir de 1964. (ROMANELLI, 2013, p. 202).

É importante destacar que segundo Romanelli (2013), as mudanças na forma de governar foram modificadas, prejudicando todas as discussões democráticas que há décadas vinham sendo pensadas para o sistema educacional brasileiro, marcando um retrocesso histórico para o projeto de Nação democrática que vinha ocorrendo, deste a prisão, perseguição e expulsão de pessoas que fossem contrárias ao governo.

Os avanços no sistema educacional não aconteceram em virtude das mudanças no sistema político brasileiro que cerceou as discussóes e debates democráticos no país, uma vez que se instalou uma ditadura militar que não permitia a discussão e debates pela sociedade civil.

O período ditatorial foi marcado pela abertura do capital econômico e de acordo com agências internacionais. Segundo Romanelli (2013, p. 202), entre junho de 1964 a janeiro de 1968, houve a "[...] assinatura de uma série de convênios entre o MEC e seus órgãos e a Agency for International Development (AID) - para assistência técnica e cooperação financeira [...]”. Esse acordo foi denominado pela autora de "Acordos MEC-Usaid", pois comprometeu a política educacional do nosso país a determinaçóes de um grupo de técnicos norte-americanos, que nada representava os interesses da sociedade brasileira, pois não atendia os reais problemas nacionais que era a falta de escolarização da população.

A educação como fator de desenvolvimento foi obscurecida no regime militar, tendo em vista a necessidade de submeter as diretrizes da escola ao mercado de trabalho, com vistas a atender os interesses liberais de abertura econômica antinacionais. Roberto Campos, então Ministro da Educação e Cultura (1968), tinha em seu discurso que "o ensino médio deveria atender à população em sua maioria, enquanto o ensino universitário fatalmente deveria continuar reservado às elites" (GHIRALDELLI Jr., 2015, 148). Fica evidente que as mudanças de perspectivas educacionais brasileiras que em 1964 tinham um caráter humanista passariam, posteriormente, a ter um caráter tecnocrático, proporcionando formação de mão de obra qualificada para atender as demandas do mercado de trabalho.

É importante destacar que segundo Ghiraldelli Jr. (2015), o caráter humanista seria aquele formado para a formação intelectual e libertadora, já a do caráter tecnocrático seria para atender o mercado de trabalho. No nosso caso para pensarmos a democracia seria o modelo mais aproximado do ideal seria o intelectual, pois a descentralização dos sistemas de ensino é fundamental para melhoria da qualidade do ensino, pois a comunidade pode participar e buscar estratégias que atendam a população.

Várias reformas foram realizadas no sistema educacional brasileiro, impactando diretamente nas políticas públicas, como afirma Romanelli (2013), dentre elas uma nova organização do ensino superior brasileiro através das leis 5.540/1968 e 5.692/1971:

[...] a política se concretizou na reforma geral do ensino, criada pelas leis 5540, de 28 de novembro de 1968, que fixou normas para a organização e funcionamento do ensino superior, seguida de outros decretos que regulamentaram, e pela lei 5.692, de 11 de agosto de 1971, que reformou o ensino de $1^{\circ}$ e $2^{\circ}$ graus. (ROMANELLI, 2013, p. 203-204).

Como afirma Romanelli (2013), percebemos que a legislação proposta pelos governos militares tinha a característica de atender as demandas do mercado de trabalho internacional, e não emancipatório como vinham sendo discutidas nos períodos democráticos que antecederam 
a regime ditatorial pois haviam vários teóricos como Anísio Teixeira, Paulo Freire entre outros que acreditavam que a educação deveria ser emancipatória.

Outro mecanismo instituído pelo governo militar foi o Ato Institucional $\mathrm{n}^{\circ} 5$ de 1968 , que retirou todas as garantias individuais do cidadão brasileiro e do próprio decreto-lei 477, que proibia qualquer manifestação no espaço das universidades brasileiras. Um completo desrespeito a livre manifestação da população, ficando evidente que o período militar foi repleto de retrocessos, pois a sociedade não podia se manifestar ou questionar os atos governamentais. Romanelli (2013), afirma que:

O Ato Institucional $\mathrm{n}^{\circ} 5$, de 13 de dezembro de 1968 , tira ao cidadão brasileiro todas as garantias individuais, quer pública, quer privada, assim como concede ao Presidente da República plenos poderes para atuar como executivo e legislativo. O Decreto-Lei 477 aplica-se exclusivamente ao corpo docente, discente e administrativo das escolas e coíbe toda e qualquer manifestaçáo de caráter político ou de protesto no âmbito das Universidades. (ROMANELLI, 2013, p. 226).

Para Romanelli (2013), o Decreto Lei 477, era uma forma de prejudicar as discussóes democráticas no âmbito universitário, marcando um profundo retrocesso, que teriam impacto direto no ensino básico, pois são nas universidades que as discussôes sobre a democratização dos sistemas de ensino.

Ghiraldelli Jr. (2015), ao analisar o período militar o divide em três momentos conforme se segue:

Uma primeira etapa ocorreu aos anos dos governos generais Castelo Branco e Costa e Silva (1964-1968); uma segunda abrangeu o governo da Junta Militar e do general Garrastazu Médici (1970-1974); finalmente, o terceiro momento foi dos governos generais Ernesto Geisel e João Baptista Figueiredo (1975-1985). (GHIRALDELLI JR., 2015, p.149).

O processo de sucessão política apontado por Ghiraldelli Jr. (2015), são somente de generais que assumem a presidência do Brasil, que vão dificultar a abertura das discussóes democráticas, principalmente para os sistemas de ensino público brasileiro, pois sempre cerceavam as discussóes com perseguiçóes e proibiçóes.

Cabe mencionar que segundo Piletti (1995, p. 126) "o regime pretendeu frear os avanços populares, o povo foi impedido de escolher seus governantes, acelerou-se a concentração da propriedade da terra e da renda, sindicatos foram invadidos e as greves impedidas pela força”, havendo casos inclusive de repressão de manifestações controladas e monitoradas pelo governo militar, no intuito de "calar" a população que pretendia discutir os rumos da nação.

\section{Consideraçóes finais}

As reformas, assim, no sistema educacional brasileiro atender, sobretudo, o processo de qualificação profissional para o mercado de trabalho, desconsiderando os debates democráticos e limitando a sociedade de expor suas opinióes, porém apesar dos argumentos, devemos considerar o processo de transformaçáo social proposto por Paulo Freire. Ganharam força as implementaçóes de leis educacionais que foram elaboradas e aprovadas durante o primeiro governo, implementadas no segundo e evidenciadas e desastrosas no terceiro, segundo afirmação de Ghiraldelli Jr. (2015, p. 149). Essa política vai comprometer, significativamente, o sistema 
educacional brasileiro do país nas duas décadas subsequentes após o fim da ditadura militar.

Diante do exposto, percebemos que as políticas educacionais implementadas no regime militar contribuíram para o cerceamento do debate democrático, uma vez que a formação dos discentes se dava sem nenhuma liberdade e senso crítico. Essa prática do regime dito ditatorial repercutiria por toda uma geração, com perseguiçóes aos professores e aos intelectuais como Anísio Teixeira e Paulo Freire, bem como coibição aos sindicatos e aos movimentos estudantis. Esse período histórico e de retrocesso no país, aponta a necessidade de se buscar um outro modelo para o sistema educacional brasileiro, um modelo cimentado na gestão escolar democrática, onde se possa priorizar a participação da comunidade nas decisóes e açôes no âmbito escolar.

\section{Referências}

DOCKHORN, Gilvan Veiga. Quando a Ordem é Segurança e o Progresso é

Desenvolvimento (1964 - 1974). Editora: EDIPUCRS, Porto Alegre, 2002.

FREIRE, Paulo. Educaçáo como prática da liberdade. Rio de Janeiro: Editora Paz e Terra, 1986.

GHIRALDELLI JR. História da Educação Brasileira. 5a ed. São Paulo: Cortez, 2015.

NAPOLITANO, Marcos. O regime militar brasileiro:1964 - 1985. Atual, São Paulo, 1998.

PILETTI, Claudino. Didática Geral. Editora Ática. São Paulo, SP. 1995.

ROMANELLI, Otaíza de Oliveira, História da Educaçáo no Brasil. 39º ed. Petrópolis: Vozes, 2013. 